\title{
APLICATIVO PARA CONTROLE DA OCUPAÇÃO DE VAGAS EM ÔNIBUS ESCOLARES
}

Gabriel Oliveira Pimentel-pimentelgabriel.contato@gmail.com

Matheus Silveira Freitas - matheus.silveira16@hotmail.com

Gabriella Castro Barbosa Costa Dalpra-gabriella@cefetmg.br

Luís Augusto Mattos Mendes - luisaugusto@cefetmg.br

Centro Federal de Educação Tecnológica de Minas Gerais - CEFET-MG - Campus III

Rua José Peres, 558, Centro

36700-001-Leopoldina-Minas Gerais

Resumo: Com a expansão da oferta de vagas no ensino público que vem ocorrendo ano após ano, tornou-se comum a migração de alunos para cidades que ofertam este tipo de ensino como oportunidade de formação (técnica ou superior). O problema abordado no presente trabalho se estabelece no cenário em que muitos alunos optam por se deslocar diariamente de sua cidade de origem para a cidade da instituição. Observa-se que, por vezes, os horários dos onibus, custeados pelas prefeituras das cidades vizinhas, não apresentam compatibilidade com o horário do término das aulas e a ocupação dos lugares disponíveis nos ônibus se dá por ordem de chegada. Dessa forma, considerando que nem todos os alunos possuem o término das aulas no mesmo horário, é gerada uma concorrência para a ocupação dos lugares e ainda há o receio de diversos alunos em ficarem sem conseguir retornar para a sua casa, uma vez. que muitos deles não possuem recurso financeiro para utilizar diariamente os serviços de transporte ofertado por empresas privadas. Este trabalho apresenta o aplicativo multiplataforma eBus, que possibilita a gestão da ocupação de vagas disponíveis nos ônibus escolares, com o intuito de auxiliar os alunos do CEFET-MG, campus Leopoldina, que são oriundos de outras cidades a efetuarem o retorno às suas residências, sem que haja a necessidade de se ausentarem das salas antes do término das aulas.

Palavras-chave: Aplicativo. Gestão do transporte. Sistema mobile.

\section{INTRODUÇÃO}

Segundo a IPM Sistemas de Gestão Pública (IPM, 2019), em uma pesquisa conjunta feita pelo site de notícias Mobile Time e a empresa de soluções em pesquisa Opinion Box, foi realizado levantamento com 1.763 brasileiros que acessam a internet e possuem smartphones, dentre os quais $62 \%$ utilizam smartphones há mais de três anos; $27 \%$ entre um e três anos; e $11 \%$ há menos de um ano. Galante (2019) afirma que "o uso de aplicativos móveis tornou-se uma cultura a qual todos nos acostumamos, dada sua presença como apps baseados em localização, ao seu desenvolvimento no espectro da realidade aumentada e virtual." Nesse contexto, é possível pensar na computação como meio de solução para diversas áreas ou setores, buscando assim melhorar a vida das pessoas em suas atividades, otimizando tempo, evitando filas e proporcionando soluções independente de sua localização geográfica. 
Segundo o INEP' " "em 2018, foram oferecidas mais de 13,5 milhões de vagas em cursos de graduação, sendo 72,9\% vagas novas e $26,9 \%$ vagas remanescentes" (BRASIL, 2019). As cidades que possuem Universidades, Centros Universitários e Institutos Federais de Educação Tecnológica ou Centros Federais de Educação Tecnológica recebem diversos alunos vindos de outras regiões para estudar.

Diante do cenário exposto, é possível observar que os novos estudantes optam por migrar a sua moradia para a cidade em que irão estudar ou decidem por permanecer morando em seu local atual e fazem o trajeto entre casa-escola todos os dias para alcançar a sua formação profissional. Entretanto, esse crescimento populacional por vezes é deixado de lado ao se pensar e propor políticas públicas de transporte, por exemplo. Ribeiro (2020) aponta que "as falhas na adaptação das estruturas de transporte público ao aumento da demanda são nítidas nas grandes cidades. O transporte público é alvo cotidiano de reclamações e, em algumas cidades, o sistema chega a ser caótico". De encontro a essa informação, Moreira (2015) aponta que " $25 \%$ dos brasileiros vai de ônibus para o trabalho ou para a escola", conforme dados levantados pela Confederação Nacional da Indústria (CNI).

Esses fatores podem influenciar negativamente no desempenho dos estudantes que utilizam de transporte público para ir à escola se, por exemplo, os horários de ônibus forem incompatíveis com as atividades acadêmicas.

Ao observar os horários dos ônibus utilizados pelos estudantes do CEFET-MG, campus Leopoldina, disponibilizados pelas prefeituras dos municípios vizinhos, nota-se uma incompatibilidade em relação aos horários de aulas, o que vem prejudicando a formação dos estudantes, haja vista que estes não assistem a última aula em sua totalidade para poderem retornar para casa. Como, por exemplo, os horários dos ônibus com alunos provindos da cidade de Cataguases, em que, são a maioria dentre os casos que se encaixam neste contexto.

Então, uma solução para este problema do gerenciamento de vagas disponíveis nos ônibus ofertados é o uso da tecnologia presente nos smartphones, item de uso frequente dos estudantes.

Com isso, este trabalho apresenta um aplicativo multiplataforma, chamado de eBus, que tem o objetivo de gerenciar a ocupação de vagas disponíveis em ônibus escolares, com o intuito de auxiliar os alunos do CEFET-MG, campus Leopoldina, que são oriundos de outras cidades a efetuarem o retorno às suas residências sem que haja a necessidade de se ausentar das salas antes do término das aulas para garantir a sua vaga no transporte.

O restante deste trabalho está organizado da seguinte forma: na Seção 2 é apresentada a Fundamentação Teórica, com os principais conceitos necessários para o entendimento do projeto desenvolvido; na Seção 3 são apresentados os Materiais e Métodos utilizados, assim como as ferramentas utilizadas no desenvolvimento do projeto; na Seção 4 tem-se a Modelagem do Sistema, abordando a prototipação das interfaces e os diagramas de Casos de Uso e EntidadeRelacionamento; na Seção 5 são detalhadas as funcionalidades presentes no sistema; e, por fim, na Seção 6 são apresentadas as Considerações Finais do presente trabalho.

\section{FUNDAMENTAÇÃO TEÓRICA}

Um sistema adequado à nova sociedade atual - que inicialmente recebeu o nome de "Sociedade da Informação", mas que acabou se desencadeando em vários termos devido ao termo de "Informação" ser interpretado como um termo sem fonte de riqueza, e que, consequentemente, se levou a termos como Sociedade do Conhecimento, Sociedade Conectada, Sociedade da Comunicação e Sociedade em Rede (FERDINAND-DRUCKER, 2002)

${ }^{1}$ Instituto Nacional de Estudos e Pesquisas Educacionais Anísio Teixeira 
(CASTELLS, 1999) - deve ser contemplado para ser um espaço a ser povoado. Propriamente deve ser adequado às devidas necessidades do ser humano necessitado a colaborar, interagir e compartilhar, sem haver uma estrutura de hierarquia, ou seja, com uma estrutura liberal com total flexibilidade a localidade, horário e motivação, que favoreça a criação e informalidade devidamente necessitada. No entanto, sistemas colaborativos em aplicativos já distribuídos são distinguidos por um determinado nível de simultaneidade, isto é, os contribuintes do sistema interagem com o sistema e entre si ao mesmo tempo (PIMENTEL et al., 2012).

Um sistema colaborativo é descrito como um sistema que possui vários usuários envolvidos em uma atividade compartilhada, geralmente de locais remotos. Os sistemas colaborativos possuem espaços virtuais próprios e específicos em que, quem são responsáveis pela projeção e desenvolvimento do sistema tem todo o poder de criar formas de trabalho e interações sociais, ou seja, novos lugares e caminhos para a convivência harmônica entre humanos. Com isso, para se entender o funcionamento de um sistema colaborativo, não basta saber apenas sobre softwares e conceitos de computação, tem que se entender a necessidade e as características do novo ser humano, o ser humano da era digital (NICOLACI-DA-COSTA e PIMENTEL, 2012). Um sistema colaborativo não deve ser restrito ao controle da realização das tarefas, como é comum de ser visto na linha corporativa e industrial.

Considerando-se então os conceitos apresentados, pode-se dizer que o eBus é uma solução colaborativa, ou seja, possui vários participantes em sua aplicação compartilhada, o que quer dizer que para seu funcionamento, é necessário à colaboração dos usuários.

\section{MATERIAIS E MÉTODOS}

Para o desenvolvimento do aplicativo eBus, seguiu-se o Método de Engenharia (FEBRACE, 2020). Após a compreensão do cenário em que o problema está envolto, passouse a etapa de levantamento de requisitos a fim de especificar a solução a ser implementada. Para tanto, após a etapa de levantamento deu-se a etapa de modelagem do sistema, momento em que foram desenvolvidos o Diagrama de Casos de Uso (DCU) e o Diagrama EntidadeRelacionamento (DER) juntamente com a prototipação das interfaces por meio do Adobe $\mathrm{XD}^{2}$. Já na etapa de implementação, foram utilizadas as tecnologias Visual Studio Code ${ }^{3}$, o framework React Native ${ }^{4}$, Javascript ${ }^{5}, P H P^{6}$ e o banco de dados $M y S Q L^{7}$.

A escolha pela plataforma Visual Studio Code ${ }^{2}$, disponibilizada pela Microsoft, se deu devido a facilidade e as quantidades de extensões que auxiliam no desenvolvimento do projeto. O framework - que é um facilitador para o desenvolvimento da aplicação - utilizado foi o React Native $^{4}$, que além de ser um framework, é descrito também como uma biblioteca Javascript ${ }^{5}$ desenvolvida pelo Facebook. A linguagem Javascript ${ }^{5}$ foi utilizada para desenvolver todo o front-end da aplicação, ou seja, tudo aquilo que o usuário vê.

Para o back-end foi utilizada a linguagem $P H P^{6}$. Entende-se por back-end tudo aquilo que o usuário não vê e que está localizada entre o front-end e o banco de dados. Para a conexão

\footnotetext{
2 https://www.adobe.com/br/products/xd/details.html

3 https://code.visualstudio.com/

4 https://reactnative.dev/

5 https://www.javascript.com/

6 https://www.php.net/

${ }^{7}$ https://www.mysql.com/products/workbench/
} 
entre o back-end e o banco de dados utilizou-se de API (Application Programming Interface) desenvolvida em $P H P^{6}$ desenvolvida na plataforma do Visual Studio Code ${ }^{2}$.

Para a criação do banco de dados, foi utilizado o sistema gerenciador de banco de dados $M y S Q L^{7}$ que foi escolhido devido à facilidade de entendimento e à popularidade entre os desenvolvedores.

\section{MODELAGEM DO SISTEMA}

Para que fosse possível o desenvolvimento do eBus, foi efetuada a prototipação das interfaces do aplicativo, a especificação das funcionalidades do sistema através do Diagrama de Casos de Uso (DCU) e a modelagem do banco de dados, através do $M y S Q L^{7}$.

\subsection{Prototipação das interfaces}

Para o desenvolvimento das interfaces do aplicativo, foi utilizado o Adobe $X D^{2}$, que é uma ferramenta de design de experiência do usuário baseada em vetor para aplicativos da Web e aplicativos móveis, desenvolvida e publicada pela Adobe Inc. As telas do sistema são apresentadas na Figura 1. Na seção 5 deste artigo, as demais telas são apresentadas juntamente com as funcionalidades.

Figura 1. Telas de Gerenciamento de Usuário. (a) Tela de login; (b) Tela de cadastro; (c) Tela de

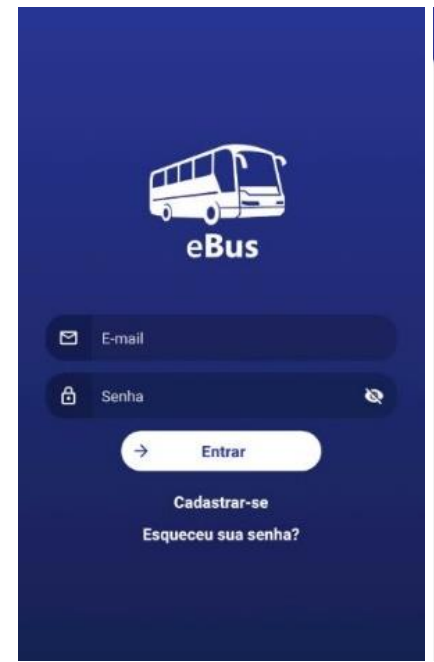

(a)

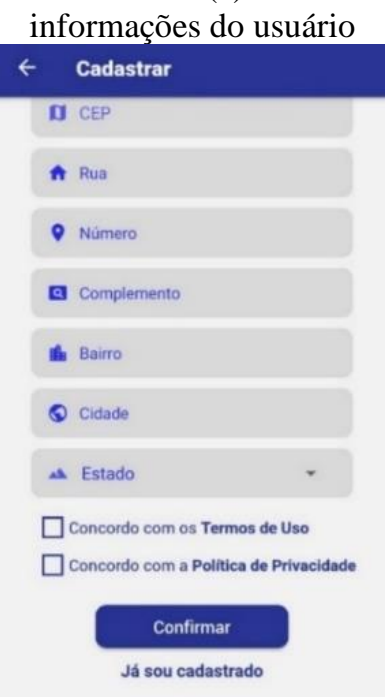

(b)

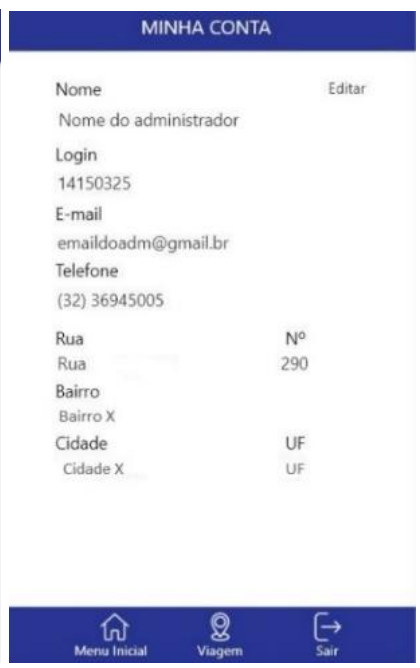

(c)

\subsection{Diagrama de Casos de Uso}

O Diagrama de Casos de Uso, que é um dos modelos propostos pela UML (Linguagem de Modelagem Unificada), tem por finalidade auxiliar na tarefa de modelar e documentar os sistemas orientados a objetos desenvolvidos. Este diagrama (Figura 2) apresenta as funcionalidades atribuídas para o Passageiro, para o Colaborador e Administrador do sistema eBus. 
Figura 2. Diagrama de Casos de Uso do aplicativo eBus

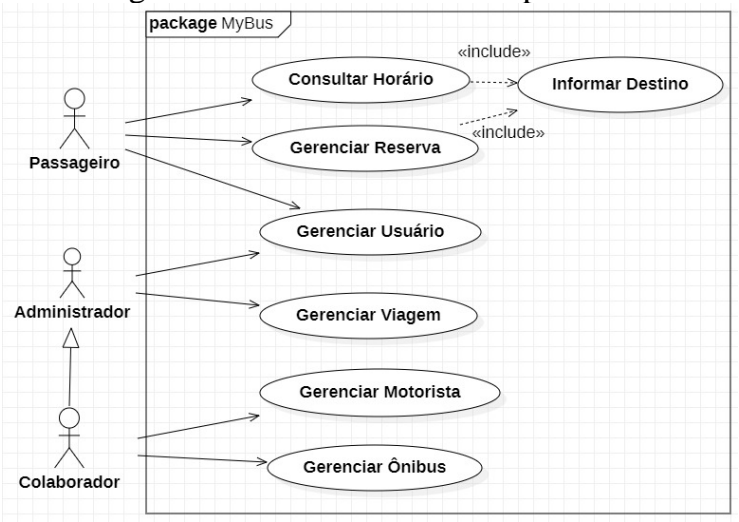

\subsection{Diagrama Entidade-Relacionamento}

De acordo com Silberschatz (2006, p.5) "O modelo de entidade/relacionamento (E-R) é baseado em uma percepção de um mundo real [...]”. A Figura 3 representa o DER do aplicativo eBus.

Figura 3. Diagrama de Entidade-Relacionamento (DER) do aplicativo eBus

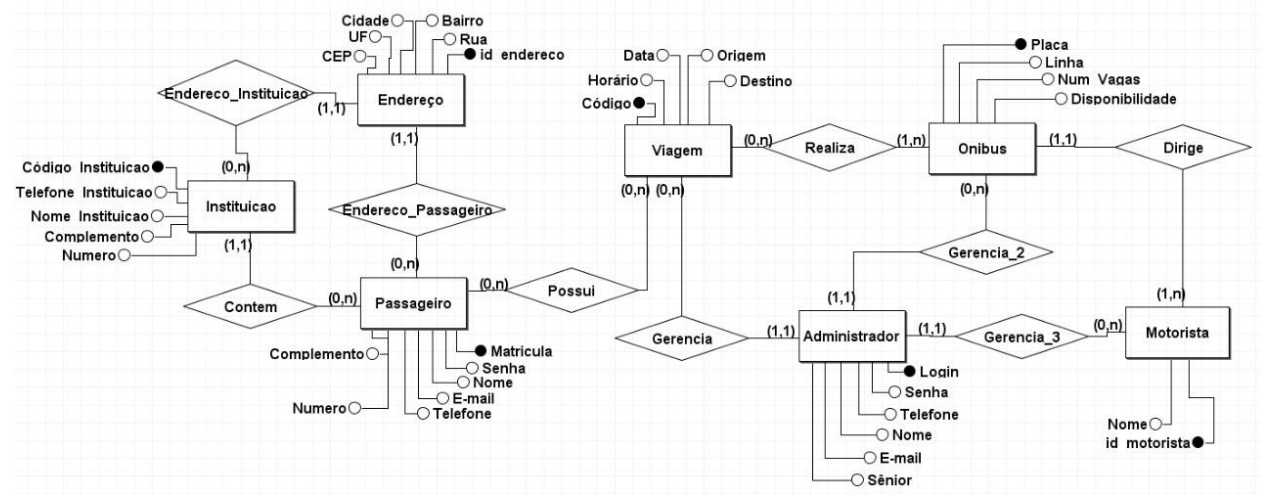

\section{FUNCIONALIDADES DO SISTEMA}

Nesta seção são descritas as funcionalidades e funções do sistema, estabelecidas de acordo com o Diagrama de Casos de Uso. As descrições permitem uma visão ampla do sistema e leva o leitor a um entendimento maior sobre as funções de cada usuário apresentados no diagrama citado.

\subsection{Gerenciar usuário}

A funcionalidade de Gerenciar Usuário engloba as funções acerca de todos os usuários do sistema, sejam eles: administrador - que é destinado para os responsáveis pela oferta do transporte; colaborador - que é destinado para os diretórios acadêmicos do corpo discente; e o usuário padrão - aquele que irá utilizar o produto. Ou seja, as funções de entrada (a), cadastro (b), informação (c), edição e exclusão do usuário, conforme é mostrado na Figura 1, que representa as telas com as respectivas funções.

Para se ter acesso ao sistema, o usuário deverá ter um e-mail e uma senha válida e já cadastrada no sistema para efetuar sua entrada. Caso seja digitado algum dado incorreto, o sistema apresentará uma mensagem informando que o dado está incorreto. No caso do usuário ainda não estar cadastrado no sistema, ele deverá efetuar seu cadastro preenchendo os dados conforme solicitados em tela. 
Após o cadastro, o usuário será redirecionado para a tela de login e, portanto, poderá acessar o aplicativo informando os dados de acesso. Após efetuar o login, ele poderá acessar a funcionalidade de edição, que se encontra na tela de Perfil onde o usuário visualiza as suas informações cadastradas e, consequentemente, poderá fazer as alterações, sendo restrito para alterações os dados únicos, como: e-mail e matrícula.

\subsection{Gerenciar viagem}

Gerenciar Viagem engloba as funcionalidades a respeito das viagens cadastradas no sistema, que contém as seguintes funções: (a) listar viagens, (b) informações de viagem, (c) editar viagem e excluir viagem. As telas são mostradas na Figura 4 e as funções são descritas em seguida.

Figura 4. Telas de Gerenciar viagem. (a) Lista de viagens; (b) Informações de viagem; (c) Edição de

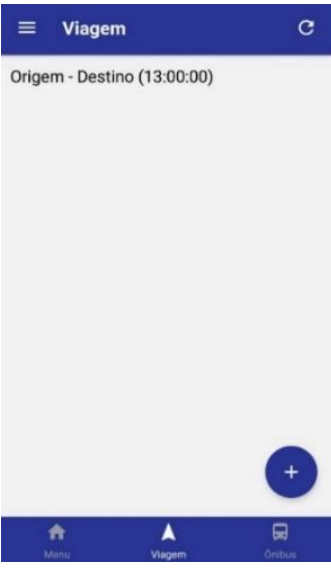

(a)

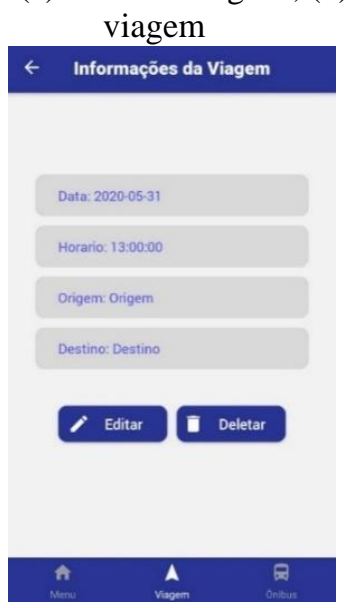

(b)

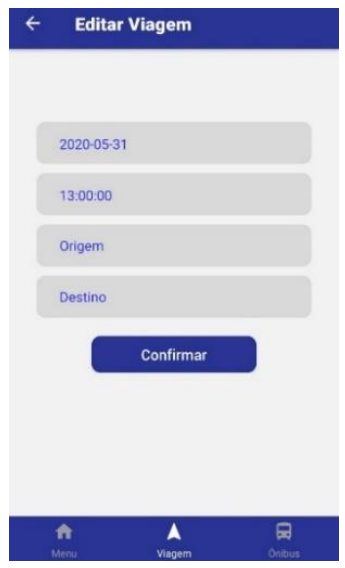

(c)

As funcionalidades de Gerenciar Viagem são designadas para o administrador e o colaborador. Dessa forma, ambos os perfis de usuários possuem as mesmas funções e permissões a cerca desse gerenciamento.

De forma descritiva, pode-se dizer que a funcionalidade de listar viagens se diz a respeito do usuário que possui essa permissão, permitindo-o listar todas as viagens cadastradas. Caso não haja nenhuma viagem cadastrada, o usuário poderá cadastrar viagem. Todas as viagens cadastradas são apresentadas na lista com as viagens do sistema.

Informações de uma determinada viagem podem ser obtidas ao selecionar a viagem desejada na lista de viagens, sendo o usuário direcionado para a tela com as informações referentes a viagem selecionada.

Com a viagem selecionada ainda é possível efetuar a edição dos dados, para isso o usuário deve editar os dados desejados. Todos os dados de viagem são de preenchimento obrigatório.

Por fim, o usuário também pode excluir uma viagem. Ao efetuar a exclusão o usuário receberá uma mensagem de sucesso e será redirecionado a tela de lista de viagens.

\subsection{Gerenciar ônibus}

Gerenciamento de ônibus incorpora as funcionalidades restritas para o usuário administrador, que tem a responsabilidade de gerenciar os dados dos ônibus presentes no sistema. As funcionalidades e suas respectivas telas são apresentadas na Figura 5. 
Figura 5. Telas de Gerenciar Ônibus. (a) lista de ônibus; (b) editar ônibus; (c) informações de ônibus

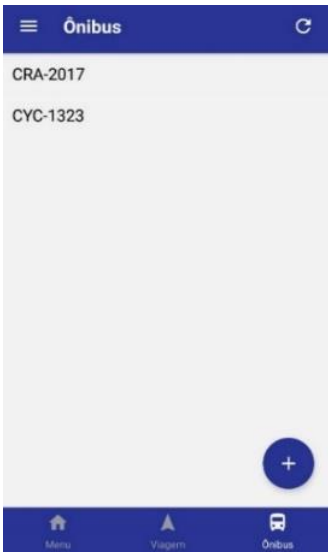

(a)

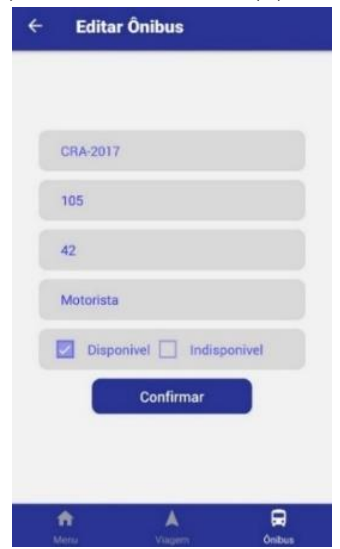

(b)

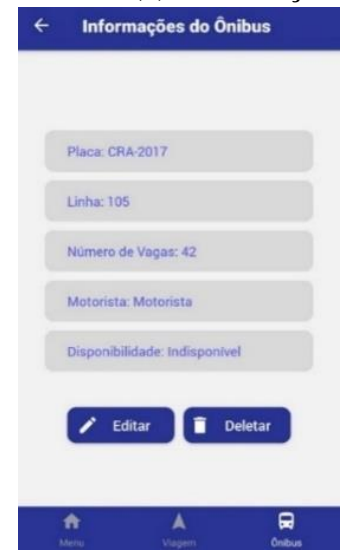

(c)

Assim como a funcionalidade de listar viagens, o sistema possui a funcionalidade de listar ônibus. Caso não haja ônibus no sistema, o administrador deve cadastrar um ônibus para a sua posterior utilização pelos usuários do sistema.

Após o cadastramento dos ônibus utilizados para realizar as viagens o responsável poderá obter informações, realizar a edição ou exclusão dos ônibus.

Caso o usuário queira obter mais informações do ônibus cadastrado, ele deve selecionar o ônibus sendo direcionado para a tela de informações que contém a placa do veículo e a disponibilidade para a realização de outras viagens.

Os passos para a edição de ônibus são semelhantes aos de edição de viagem, bastando informar os dados necessários que são solicitados pelo sistema. Ao final, o sistema apresentará uma mensagem ao usuário.

Para excluir um ônibus, o usuário deve acessar a tela de informações do ônibus selecionando-o e, em seguida, o administrador será redirecionado para a tela de lista de ônibus, caso a exclusão tenha sido efetuada com sucesso. A alteração na lista de ônibus poderá ser verificada recarregando a listagem de ônibus.

\subsection{Gerenciar motorista}

As funcionalidades de gerenciar motorista são de total responsabilidade dos administradores do sistema, estas devem ser gerenciadas em conjunto com o gerenciamento dos ônibus ofertados (Figura 5).

A decisão pelo gerenciamento conjunto do motorista com o ônibus visa facilitar o controle pelos administradores do sistema.

\subsection{Gerenciar reserva}

O gerenciamento de reserva engloba as funcionalidades destinadas aos usuários que irão utilizar o aplicativo, sejam elas: (a) a realização da reserva e (b) a verificação da reserva realizada (Figura 6). 
Figura 6. Telas de Gerenciar Reserva.(a) Realização da Reserva; (b)Verificação da Reserva

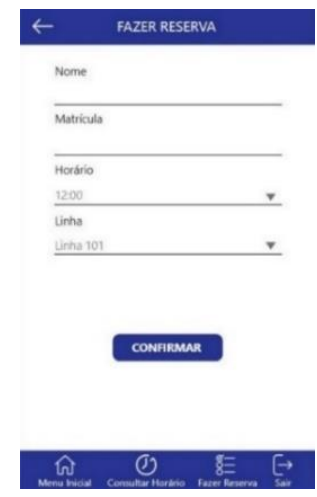

(a)
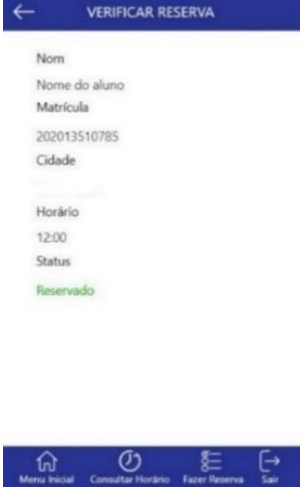

(b)

Assim, a realização da reserva apresentada na Figura 6 (a) exibe ao usuário as viagens ofertadas e disponíveis. Os dados das viagens exibidas consideram a cidade de sua instituição possibilitando ao usuário visualizar apenas as viagens que são destinadas a ele.

Ao selecionar a viagem desejada, o usuário é redirecionado para a tela de confirmação da reserva, no caso de o ônibus possuir vagas disponíveis. Se a reserva for efetuada, o sistema apresentará a mensagem "realização da reserva foi feita com sucesso". Caso contrário, será exibida uma mensagem informando a indisponibilidade do ônibus.

Após a confirmação, o sistema direcionará o usuário para a tela permitindo-o verificar as informações de sua reserva (Figura 6(b)) contendo as informações úteis da viagem e o horário selecionado. Contudo, caso o usuário opte por desistir da reserva ou tentar efetuar uma reserva em outro horário será necessário excluir a reserva efetuada disponibilizando a vaga para outro usuário.

\subsection{Consultar horários}

A funcionalidade que diz a respeito de consultar horários é destinada aos usuários que irão fazer o uso do aplicativo e, como o próprio título da subseção diz, é para o usuário poder realizar as consultas dos horários das viagens cadastradas e disponíveis no sistema. Além disso, as funcionalidades são descritas conforme Figura 7.

A funcionalidade consultar horários apresenta o mesmo resultado a todos os usuários que fazem o uso do aplicativo. Dessa forma, todos os horários e viagens cadastradas podem ser visualizadas.

Figura 7. Protótipo de tela de consultar horários

\begin{tabular}{c|c}
$\leftarrow$ \\
\hline DESTINO: \\
\hline PARTIDA & CHEGADA \\
$12: 00$ & $12: 30$ \\
$17: 00$ & $17: 30$ \\
$19: 00$ & $19: 30$ \\
$22: 30$ & $23: 00$
\end{tabular}

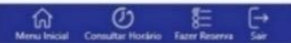

\subsection{Informar destino}

Por fim, a funcionalidade de informar destino se dá através da realização da reserva. Sendo assim, para o usuário realizar uma reserva, ele deve informar seu destino. Caso contrário, o 
usuário não poderá realizar a reserva, já que o sistema permite efetuar reserva apenas após ser informado o destino escolhido pelo usuário, conforme mostra a Figura 6 (a).

\section{CONSIDERAÇÕES FINAIS}

Durante a realização da pesquisa e implementação do aplicativo eBus, pode-se observar diversas questões que influenciam no cenário do problema em voga, tais como horários de ônibus distintos do término das aulas, número de alunos que utilizam do ônibus escolar e disponibilidade de vagas versus horários de ônibus ofertados. Nesse sentido, a solução apresentada para o problema do controle da ocupação de vagas em ônibus escolares, na qual o projeto foi pautado, teve como foco primordial, em suas etapas, a demanda dos alunos que utilizam este meio de transporte.

Teste funcionais do eBus foram realizados pela equipe desenvolvedora, porém devido à suspensão do calendário escolar desde 15 de março de 2020, motivada pela pandemia de COVID-19, os testes do aplicativo junto ao público alvo ainda não foram realizados. No entanto, esta fase está planejada para ocorrer assim que as atividades escolares presenciais forem retomadas.

Espera-se que o aplicativo eBus oportunize aos responsáveis pelo transporte escolar um gerenciamento mais efetivo dos usuários dos ônibus escolares, possibilitando a alocação de recursos de forma mais assertiva. Além disso, acredita-se que com a organização da ocupação das vagas dos ônibus escolares será oportunizado aos alunos uma maior tranquilidade para assistirem às aulas até o fim. Dessa forma, resolvendo o impasse que os alunos vivenciam entre perder aula e retornar para casa ou assistir a última aula até o fim e não ter a certeza de retornar para casa. Diante ao exposto, almeja-se que o eBus proporcione aos envolvidos no uso de transporte escolar impactos positivos evidenciando o controle ágil e prático pelas partes envolvidas, além da possibilidade de oportunizar aos alunos um melhor aproveitamento das aulas.

\section{REFERÊNCIAS}

BRASIL. Instituto Nacional de Estudos e Pesquisas Educacionais Anísio Teixeira (Inep). Censo da Educação Superior 2018: Notas Estatísticas. Brasília, 2019. Disponível em: http://download.inep.gov.br/educacao_superior/censo_superior/documentos/2019/censo_da_e ducacao_superior_2018-notas_estatisticas.pdf. Acesso em: 15 setembro 2020.

CASTELLS, Manuel. A sociedade em rede. São Paulo: Paz e Terra, 1999.

FEBRACE. Metodologia de Engenharia. Disponível em: https://febrace.org.br/projetos/metodologia-de-engenharia/\#.XtWfmzpKhPY. Acesso em: 15 setembro 2020.

FERDINAND-DRUCKER, Peter. O melhor de Peter Drucker: obra completa. São Paulo: Nobel, 2002.

GALANTE, Vitor. 7 Tendências de desenvolvimento mobile em 2019. Disponível em: https://usemobile.com.br/7-tendencias-de-desenvolvimento-mobile-em-2019/. Acesso em: 15 setembro 2020. 
IPM. Uso de aplicativos mobile cresce entre brasileiros com popularização dos smartphones. Disponível em: https://www.ipm.com.br/blog/uso-de-aplicativos-mobilecresce-entre-brasileiros-com-popularizacao-dos-smartphones/. Acesso em: 15 setembro 2020.

MOREIRA, Marli. Um em cada quatro brasileiros usa o ônibus como principal meio de transporte. São $\quad$ Paulo, $2015 . \quad$ Disponível em: http://agenciabrasil.ebc.com.br/geral/noticia/2015-10/um-em-cada-quatro-brasileiros-usa-oonibus-como-principal-meio-de-transporte. Acesso em: 15 setembro 2020.

NICOLACI-DA-COSTA, Ana Maria; PIMENTEL, Mariano. Sistemas colaborativos para uma nova sociedade e um novo ser humano. In: PIMENTEL, Mariano; FUKS, Hugo (org.). Sistemas Colaborativos. Rio de Janeiro: Campus, 2012. p. 3-15. Disponível em: https://sistemascolaborativos.uniriotec.br/. Acesso em: 15 setembro 2020.

PIMENTEL, Mariano; GEROSA, Marco Aurélio; FUKS, Hugo. Sistemas de comunicação para colaboração. In: PIMENTEL, Mario; FUKS, Hugo (org.). Sistemas Colaborativos. Rio de Janeiro: Campus, 2012. p. 65-93. Disponível em: https://sistemascolaborativos.uniriotec.br/. Acesso em: 15 setembro 2020.

RIBEIRO, Amarolina. Efeitos do êxodo rural nos países subdesenvolvidos. 2020. Disponível em: $\quad$ https://alunosonline.uol.com.br/geografia/efeitos-exodo-rural-nos-paisessubdesenvolvidos.html. Acesso em: 15 setembro 2020.

SILBERSCHATZ, Abraham; KORTH, Henry F. Sistema de banco de dados. $5^{\text {a }}$ ed. Rio de Janeiro: Elsevier, 2006.

\section{APPLICATION FOR OCCUPATION CONTROL OF VACANCIES ON SCHOOL BUSES}

Abstract: With the expansion of the offer of places in public education that has been occurring year after year, it has become common for students to migrate to cities that offer this type of education on as a training opportunity (technical or higher). The problem addressed in this project is established in the scene, in which many students choose to move daily from their hometown to the institution's city. It's observed that, sometimes, the bus schedules, paid for by the city hall of the student hometown, aren't compatible with the time of the end of classes and the occupation of the available places on the buses is on a first come, first served basis. So, considering that not all students have the end of classes at the same time, a competition is generated for the occupation of bus and there is still the fear of several students of being unable to return to their home, since many of them they don't have financial resources to use transportation's services on a daily basis, carried out by privates companies. The presented project proposes to develop a multiplatform mobile system that allows the management of available places on buses, in order to help students from the CEFET-MG, campus Leopoldina, who come from other cities, to return to their homes, without the need to leave the rooms before the end of classes.

Keywords: App. Transport management. Mobile system. 